\title{
Voltage Control for Unbalanced Low Voltage Grids Using a Decoupled-Phase On-Load Tap-Changer Transformer and Photovoltaic Inverters
}

\author{
Zecchino, Antonio; Marinelli, Mattia; Hu, Junjie; Coppo, Massimiliano ; Turri, Roberto
}

Published in:

Proceedings of 2015 50th International Universities Power Engineering Conference (UPEC)

Link to article, DOI:

10.1109/UPEC.2015.7339880

Publication date:

2015

Document Version

Peer reviewed version

Link back to DTU Orbit

Citation (APA):

Zecchino, A., Marinelli, M., Hu, J., Coppo, M., \& Turri, R. (2015). Voltage Control for Unbalanced Low Voltage Grids Using a Decoupled-Phase On-Load Tap-Changer Transformer and Photovoltaic Inverters. In Proceedings of 201550 th International Universities Power Engineering Conference (UPEC) IEEE. https://doi.org/10.1109/UPEC.2015.7339880

\section{General rights}

Copyright and moral rights for the publications made accessible in the public portal are retained by the authors and/or other copyright owners and it is a condition of accessing publications that users recognise and abide by the legal requirements associated with these rights.

- Users may download and print one copy of any publication from the public portal for the purpose of private study or research.

- You may not further distribute the material or use it for any profit-making activity or commercial gain

- You may freely distribute the URL identifying the publication in the public portal 


\section{Voltage Control for Unbalanced Low Voltage Grids Using a Decoupled-Phase On-Load Tap-Changer Transformer and Photovoltaic Inverters}

\author{
Antonio Zecchino, Mattia Marinelli, Junjie $\mathrm{Hu}$ \\ Department of Electrical Engineering (CEE) \\ DTU - Technical University of Denmark \\ Contact: antozec@elektro.dtu.dk
}

\author{
Massimiliano Coppo, Roberto Turri \\ Department of Industrial Engineering \\ University of Padova, Italy
}

\begin{abstract}
This paper presents modeling and analysis of the potential benefits of joint actions of a MV/LV three-phase power distribution transformer with independent on-load tap-changer control on each phase and photovoltaic inverters provided with reactive power control capability, in terms of accommodating more renewable generations in the $L V$ grid. The potential benefits are investigated in terms of voltage unbalance reduction and local voltage regulation. 24-hours root-mean-square dynamics simulation studies have been carried out with timestep of 1 second using 10-mins resolution consumption and production profiles. A totally passive real Danish low voltage distribution network is used for the grid topology as well as for the characterization of loads profiles, while the production ones are empirically defined under assumptions in scenarios with different level of photovoltaic penetration and grade of unbalance.
\end{abstract}

Index Terms- On-Load Tap-Changer, Unbalanced Low Voltage Grid, Photovoltaic Hosting Capacity, Photovoltaic Inverter, Power Transformer, Reactive Power Control, Voltage Control

\section{INTRODUCTION}

Traditionally, Danish low voltage grids are characterized by unbalanced layout of the household electrical installation. The voltage unbalance effect is even higher due to the users' single-phase connections of small generating units which nowadays are partially replacing conventional generators, with a consequent reduction of the regulation capability in the overall electrical system. In the specific case of the increasing penetration of fluctuating photovoltaic generation, especially if unbalanced, distribution system operators (DSO) are further challenged by possible local overvoltages unevenly distributed on the three phases with the risk of violating the allowed voltage band [1], [2]. Therefore, with the aim to avoid expensive expansion investments by network operators, several studies have been performed proposing solutions to reduce the mentioned overvoltage phenomena. The proposed strategies in this regard include voltage control using reactive power provision from PV inverters [2], [3], active power derating of the $\mathrm{PV}$ production in case of overvoltage conditions [4] and voltage control at the LV side of the MV/LV transformer by on-load tap changers (OLTC) [5].
Specifically, in [6]-[9] the voltage control method focuses on the coordination of OLTC operation and reactive power exchange between the DSO and the PV inverters.

All the research activities discussed above concerning the OLTC applications focus on the use of traditional synchronized tap-changer actions on the three phases, since they do not consider the different voltage conditions in low voltage networks due to the single-phase connection of DGs. This kind of connection, typical of PV inverters, could worsen the power flow unbalance already existing in LV distribution networks.

In [10] an analysis of the effectiveness of a distribution transformer with decoupled phase on-load tap-change capability is performed, considering the same passive low voltage network used in this study.

The novelty of this work is the investigation of the potential benefits of combining the actions of OLTC distribution transformers provided with single-phase-independent tapping capability and of automatic reactive power management systems by the PV inverters in a real Danish low voltage grid. Analyses are performed in scenarios with different PV penetration levels, comparing situations with or without tap actions or reactive power regulation by PVs.

\section{Methodology}

All the elements of the real reference low voltage network, the OLTC and the PV plants as well have been modeled in DIgSILENT PowerFactory software environment, which allowed 24-hours RMS dynamics simulation studies with time-step of 1 second using 10-mins resolution consumption and production profiles.

\section{A. Danish LV grid}

The real network considered for the analysis is a DONG Energy network located in Bistrup, a village around $20 \mathrm{~km}$ out of Copenhagen. It is a 6- bus totally passive low voltage feeder connected to the MV network through a 10/0.4 kV transformer, as shown in Fig. 1. The short circuit power of the main network is 20 MVA [11]. 


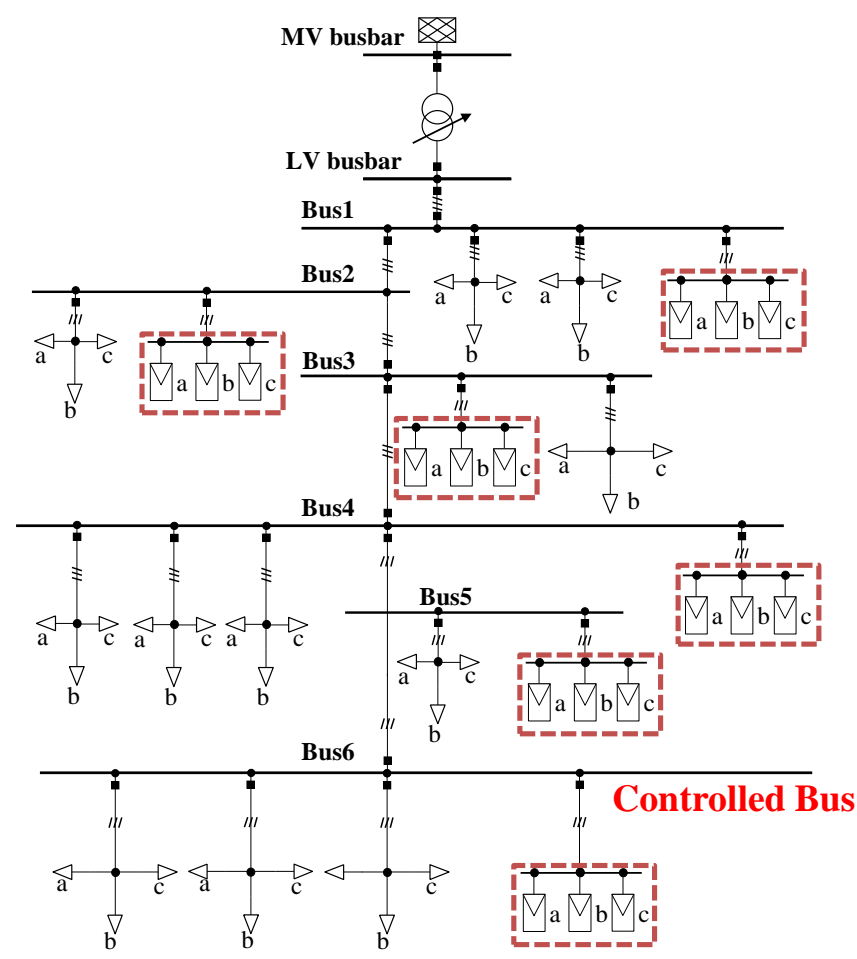

Fig. 1. Single line diagram representation of the real Danish LV network Since the real grid is totally passive, the PV units are manually added according to specific assumptions.

Real measurements on voltages, currents and powers on the three phases of the busbars have been considered in order to characterize the 24-hour-long consumption profiles in terms of active and reactive power of the 33 single-phase loads (Fig. 2). The total energy absorption resulted to be about 775 $\mathrm{kWh}$, with a mean power of $32.3 \mathrm{~kW}$. The daily energy losses amounted to $8.9 \mathrm{kWh}$, i.e. the $1.14 \%$ of the total energy absorbed from the MV grid. The total load energy and mean power amounts for each phase are reported in Table I.

TABLE I

TOTAL LOAD ENERGY ABSORBED IN THE 24 HOURS AND MEAN POWER

\begin{tabular}{|c|c|c|c|}
\hline & Phase a & Phase b & Phase c \\
\hline Energy [kWh] & 364.3 & 190.6 & 220.6 \\
\hline Mean Power [kW] & 15.2 & 7.9 & 9.2 \\
\hline
\end{tabular}

\section{B. OLTC modeling}

In order to perform independent single-phase changes of the transformation ratios, the three-phase OLTC Delta-Wye transformer has been modeled through three single-phase units independently controlled, whose secondary sides are connected between an earthed neutral point and a different phase of the LV grid under exam.

Each single-phase transformer has been set with rated power $P_{n}$ of $210 \mathrm{kVA}$, short-circuit voltage related to the positive sequence impedance $V_{c c}$ equal to $4 \%$ of the primary side nominal one, ratio of positive sequence impedance and resistance $X / R$ of 10 and both the off-load current $i_{0 \%}$ and offload power $P_{0}$ set to zero. The decision of neglecting the inner iron losses is justified by the fact that the results
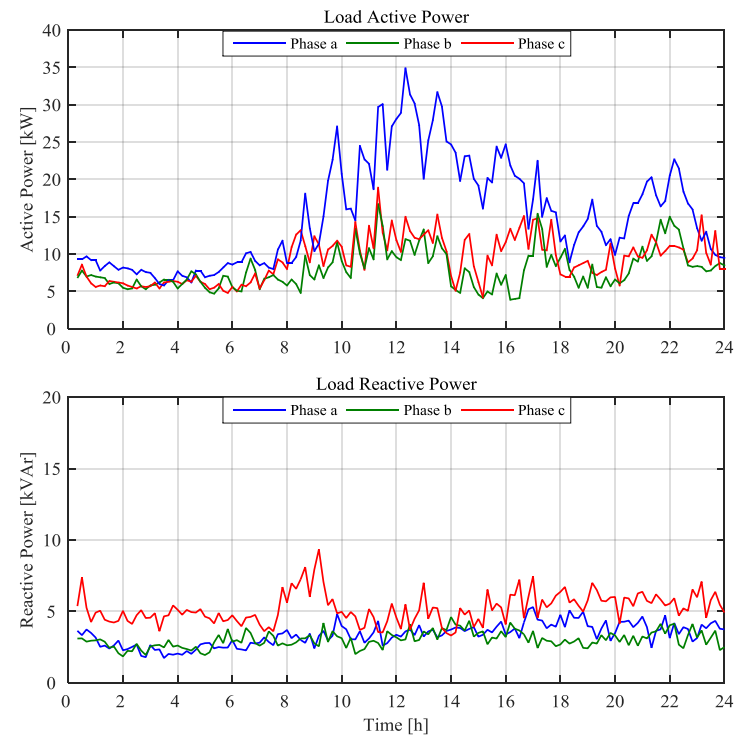

Fig. 2. Active and reactive power absorption on the three phases.

analysis do not present any influence in terms of comparisons of different scenarios, since all of them are characterized by the same amount of off-load inner losses. For example, considering typical indicative values of $i_{0 \%}$ and $P_{0}$ respectively of $1.4 \%$ and $0.42 \mathrm{~kW}$ for each single-phase transformer, the total daily amount of off-load would have been $30 \mathrm{kWh}$.

To model the three-phase OLTC transformer actions, each single-phase tap-changer is assumed to be associated to the same control scheme. Specifically, in this study the ratio variation is obtained through the proportional controller shown in Fig. 3: the tap position is changed continuously according to the instantaneous measurement of the phase voltage at the controlled bus. The curve has been defined setting the output voltage variation range to $\pm 5 \%$ of the rated value $V_{n}$ and the voltage dependency sensitivity to 0.001 p.u. - it represents the precision of the voltage measurements.

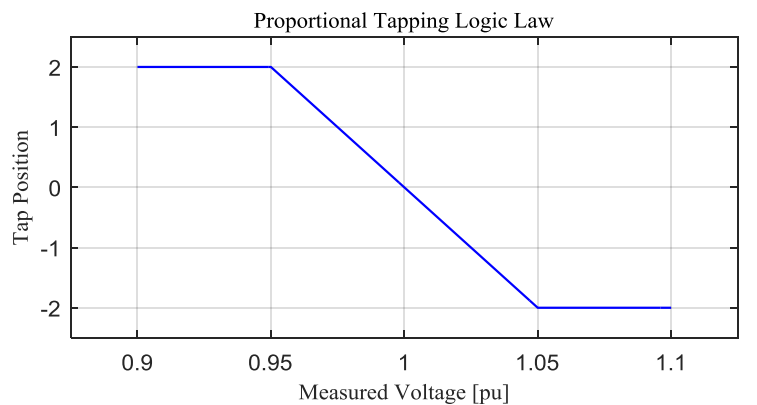

Fig. 3. Proportional Tapping Logic Law. In order to obtain the above-said output voltage variation range, it has been set that each tap unit corresponds to an output voltage variation of $2.5 \%$ of $V_{n}$, since \pm 2 has been considered as limit tap positions.

\section{Loads and PV modeling}

Load active and reactive power profiles are characterized by real measurement data with a 10 minutes resolution during a 24-hours interval. With the same time discretization, the PV 
production profiles are defined, according to the different scenarios considered.

Loads need to be represented as constant impedance units, while PVs as constant power ones. When running RMS simulations in DIgSILENT PowerFactory software environment, the load model refers to a constant impedance unit. Therefore, in order to reproduce the real behavior of PVs, it has been necessary to refer to the ZIP Theory [12], by introducing a sort of correction to the PV active power input values. Equation (1) shows the procedure, where $P_{\text {ref }}$ is the active power read from the text file and $P_{\text {mod }}$ is the one which will effectively be applied to the PV unit model:

$$
P_{\text {mod }}=P_{r e f}(1 / \mathrm{V})^{2}
$$

Of course the same considerations are valid also with reference to the reactive power.

A reference 24-hours active power production profile of a 1 $\mathrm{kWp}$ PV plant is used to allow the definition of all the input values for each generating unit in each scenario considered (Fig. 4).

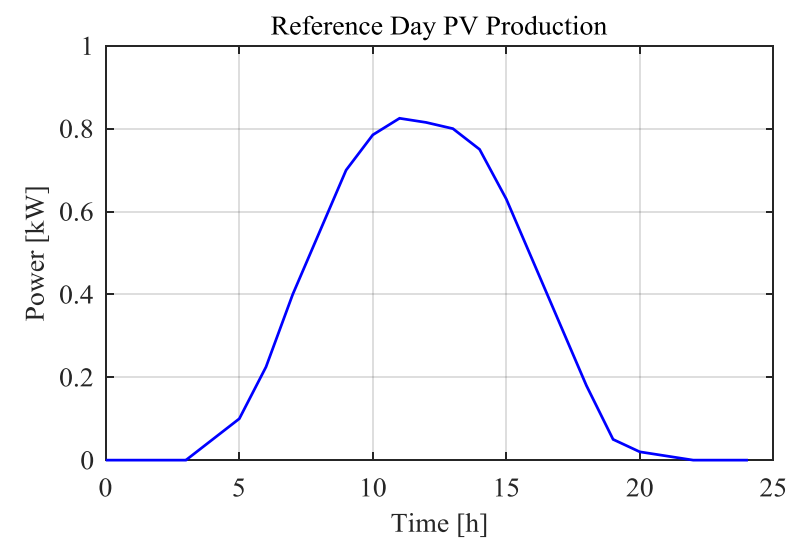

Fig. 4. Typical daily PV production of a $1 \mathrm{kWp} \mathrm{PV} \mathrm{plant} \mathrm{in} \mathrm{clear-sky}$ condition with panels pointing South and $30^{\circ}$ of inclination.

Since nowadays the Danish grid code does not provide for any technical guidelines about the reactive power management by the small distributed generation plants connected to the LV network, an arbitrary algorithm which could be efficient and practically conform to the European guideline is implemented. Considering that Denmark, Italy and Germany belong to the same synchronous region, the function of the controller is defined according to technical rules for low voltage active users stated by the Italian and German Technical Standards - respectively CEI 0-21 [13] and VDE-AR-N 4105 [14]. These standards set different requirements on the reactive power production by the PV inverters with rated power above $3 \mathrm{~kW}$ and define several variations depending on the size of the plant together with specific DSO-users agreements.

Starting from these guidelines and with reference to [3], a new regulation function is therefore created, with both voltage and active power dependence (2):
The implemented reactive power control capability (RPC capability) from PVs is depicted in Fig. 5.

Since in the simulation tool PVs are implemented with the same model as the load units, they thus need to be considered as 'active load'. Positive values of reactive power correspond to an inductive nature, which means that reactive power gets absorbed by the inverter; on the other hand - if negative - it behaves like a capacitor and Q is injected into the grid.

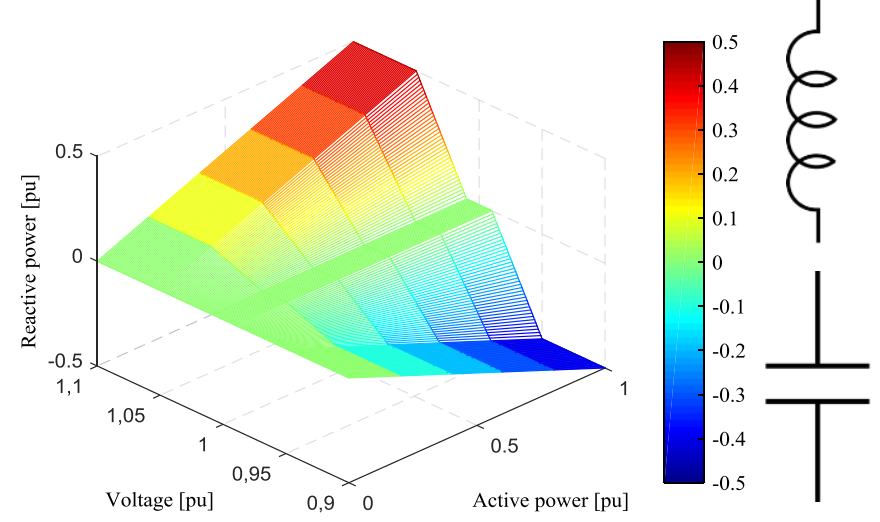

Fig. 5. Reactive Power Control capability for PV inverter.

According to the European Standard EN 50160 [15], voltage limits have been set to $\pm 10 \%$ the nominal voltage $V_{n}$, i.e. $V_{\min }=0.9$ p.u. and $V_{\max }=1.1$ p.u. The green area between $0.99 V_{n}$ and $1.01 V_{n}$ represents a dead band without any reactive power controls regardless the instantaneous produced active power. The red area identifies the operation in overvoltage conditions, when the inverter absorbs reactive power up to 0.5 p.u. in order to lower the voltages. Symmetrically, the inverter injects up to 0.5 p.u. of reactive power when operation conditions are in the blue undervoltage area.

\section{Simulations}

\section{A. Scenarios and operative cases}

In order to evaluate the controllers' effectiveness under different operating conditions, several PV penetration scenarios and operative cases are considered and straightaway introduced.

As previously said, since the reference real LV grid is merely passive, $\mathrm{PV}$ production profiles need to be empirically defined: each scenario is therefore characterized by a certain installed peak power and its distribution among the three phases in terms of grade of unbalance, as shown in Table II.

TABLE II

CHARACTERIZATION OF DIFFERENT ANALYZED SCENARIOS

\begin{tabular}{|c|c|c|}
\hline Scenario & $\begin{array}{c}\text { Total installed PV power } \\
{[\mathrm{kWp}]}\end{array}$ & $\begin{array}{c}\text { Installed power distribution } \\
\text { among the three phases [\%] }\end{array}$ \\
\hline 1 & 140 & $\mathrm{a}, \mathrm{b}(50,50)$ \\
\hline 2 & 210 & $\mathrm{a}, \mathrm{b}(50,50)$ \\
\hline 3 & 245 & $\mathrm{a}, \mathrm{b}, \mathrm{c}(50,30,20)$ \\
\hline 4 & 280 & $\mathrm{a}, \mathrm{b}, \mathrm{c}(50,30,20)$ \\
\hline
\end{tabular}


Each scenario is studied performing comparisons between three distinct operative cases characterized by as many combinations of the two controllers:

1. Base Case ("Base"): neither the OLTC nor the reactive power control system by PVs is activated: this case is used as absolute reference for the comparisons;

2. 1-Phase Case ("OLTC"): the OLTC actions are operated independently on the three phases, referring each single-phase tap action to corresponding singlephase phase-neutral voltage measurements. This operative case does not include the reactive power regulation by $\mathrm{PVs}$;

3. 1-Phase Case with $Q$ reg. by PVs ("OLTC + Qreg”): in addition to the independent tap adjustment activities by OLTCs, now also the local reactive power provision control by $\mathrm{PV}$ inverters is activated.

\section{B. Results}

For each simulation, graphical results are given in terms of phase-neutral voltage profiles over the 24 hours, with particular attention to the deviations from the nominal value at bus 6 (i.e. the controlled bus). In addition, numerical results are reported in Table III, where values of the maximum deviation of the phase-neutral voltages at bus 6 and maximum and mean values of both the Voltage Unbalance Factor (VUF, defined in (3) [16]) and the neutral conductor potential at the same point of the grid are presented.

$$
V U F_{\%}=V_{\text {negative seq }} / V_{\text {positive seq }} \cdot 100
$$

Fig. 6 and Fig. 7 show the phase-neutral voltage profiles at bus 6 over the 24 hours, comparing the three operative cases in the scenarios \#1 and \#2, which refer respectively to the situation of a PV installed power of 140 and $210 \mathrm{kWp}$, evenly distributed among the phases a and $b$, without considering any power injection in phase c. Focusing on the first plot, by comparing the base case to the OLTC case, it can be seen that due to independent phase regulations the three phase-neutral voltages get closer to 1 p.u.. The additional reactive power control by PVs allows a further decrease of the deviation from the rated value, even though the differences from the previous operative case do not appear so relevant. Similar considerations are deducible from the results of scenario \#2, which specifically present a more appreciable reduction of the phase-neutral voltage deviation when the local reactive power provision control is included, allowing the voltages to stay within the acceptable range of $\pm 10 \%$ of $V_{n}$. Comparing scenarios \#1 and \#2, it can be concluded that, due to the joint actions of OLTCs and local Q provision control, the PV hosting capacity of the LV grid for this particular grade of unbalance grows from $140 \mathrm{~kW}$ to $210 \mathrm{~kW}$.

The simulation results of scenarios \#3 and \#4, which refer to a PV installed power of 245 and $280 \mathrm{kWp}$, are reported respectively in Fig. 8 and Fig. 9 in terms of phase-neutral voltages. Both are characterized by the same grade of unbalance, defined by the following distribution among the

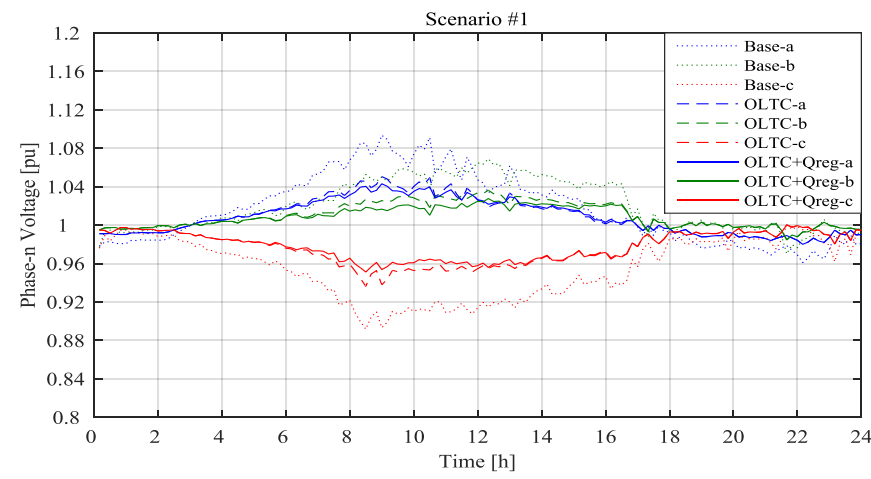

Fig. 6. Phase-neutral voltages at bus 6 for the three different operative cases in the Scenario \#1.

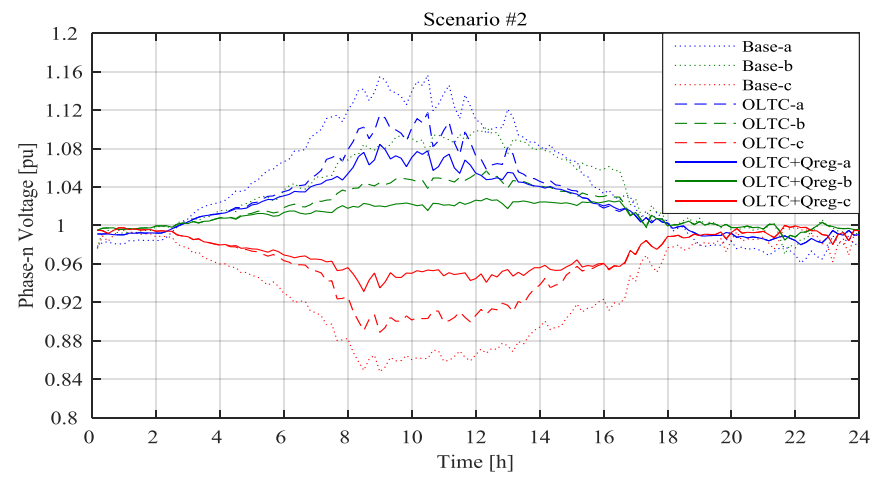

Fig. 7. Phase-neutral voltages at bus 6 for the three different operative cases in the Scenario \#2.

three phases of the total installed power: $50 \%$ is connected to phase a, $30 \%$ to phase $b$ and $20 \%$ to phase c.

It can be seen that in scenario \#3 the phase-independent OLTC actions allow a reduction of the phase-neutral voltage deviations compared to the base case, and again the situation is even better if the additional Q regulation control by PVs is performed. The same considerations are valid in scenario \#4 too, in which the addition of the local $\mathrm{Q}$ provision control allows to keep the voltages within the acceptable range of $\pm 10 \%$ of $V_{n}$, thing that otherwise would not have been possible. This aspect leads to the conclusion that, for this

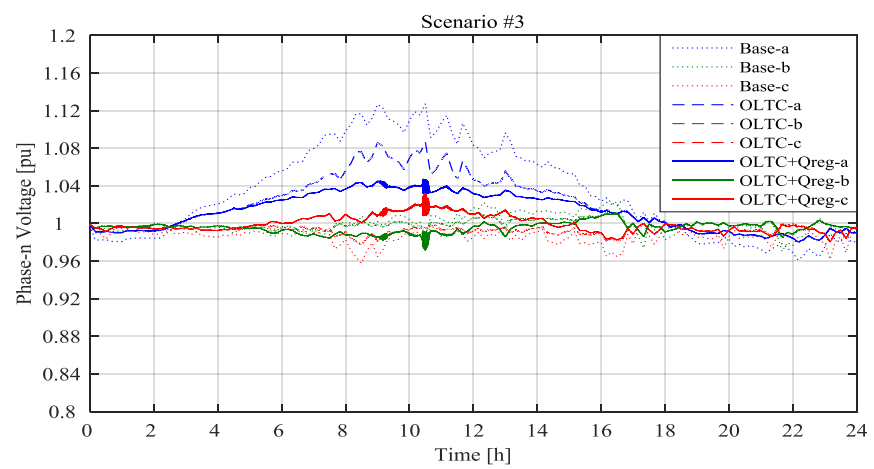

Fig. 8. Phase-neutral voltages at bus 6 for the three different operative cases in the Scenario \#3. 
particular grade of unbalance of distributed generation, the PV hosting capacity has grown from 245 to $280 \mathrm{~kW}$ thanks to the combined actions of the OLTCs and the local Q control.

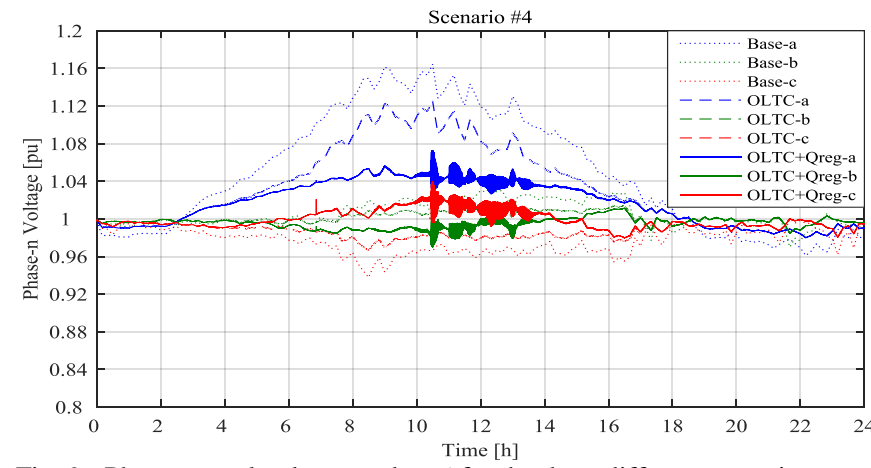

Fig. 9. Phase-neutral voltages at bus 6 for the three different operative cases in the Scenario \#4.

As it can be noticed in Fig. 8 and Fig. 9, the phase-neutral voltages at bus 6 are characterized by many undesired fluctuations: the cause is related to the high gain of the reactive power regulation law (Fig. 5), which makes the control system unstable. Due to this, it has been considered a different $Q=f(V, P)$ curve (Fig. 10), which, compared to the previous one, presents the same dead band but a different gain, having now a continuous growth/decrease from the limit voltage values of the dead band to the extreme voltage values of the regulation algorithm.

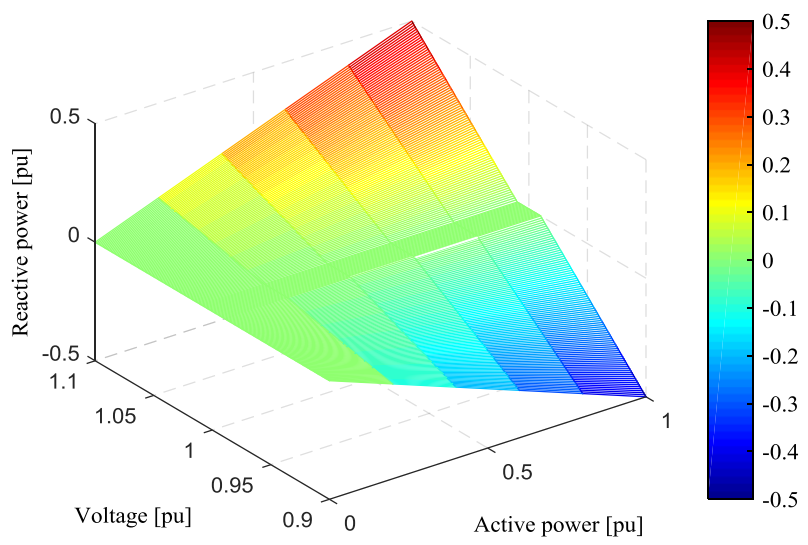

Fig. 10. New Reactive Power Control capability for PV inverter.

Thanks to this modification, the undesired fluctuations are avoided: according to the new regulation law, the phaseneutral voltages trends at bus 6 in the scenario \#4 are replotted in Fig. 11.

In Table III an overall result overview is reported: values of the maximum deviation of the phase-neutral voltages at bus 6 and maximum and mean values of both the VUF and the neutral conductor potential at the same bus are presented for each operative case in each scenario.

The above-described considerations about the phaseneutral voltages deviations are hereby numerically explicated in the third column. Moreover, further positive effects can

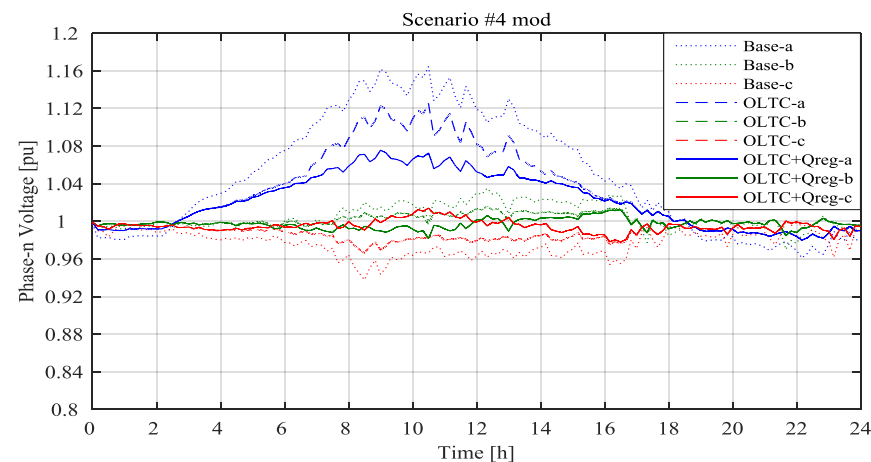

Fig. 11. Phase-neutral voltages at bus 6 for the three different operative cases in the Scenario \#4 using the new RPC capability.

clearly be identified upon the neutral-ground voltages: even though it increases because of the phase independent OLTC actions, the additional $\mathrm{Q}$ provision system by PVs makes it decreasing down to values even below the one related to the base case, both in terms of mean and maximum values.

On the other hand, concerning the VUF, criticalities are found in terms of both mean and maximum values when the two control algorithms work simultaneously, especially when the amounts of total PV installed power is higher - i.e. in scenarios \#3 and \#4. The reason is related to the positive and negative sequences amounts: since the $\mathrm{Q}$ provision is just based on active power and phase-neutral voltage measurements, the implemented reactive power control law does not take into account any sequence-related index. Therefore, since the VUF is not supposed to be controlled by the tap logic system neither by the reactive power control, the DSO is supposed to consider this aspect and look for other regulating actions elsewhere.

TABLE III

RESULT OVERVIEW FOR ANALYZED SCENARIOS

\begin{tabular}{|c|c|c|c|c|c|c|}
\hline \multirow[t]{2}{*}{ Scenario } & \multirow[t]{2}{*}{ Operative Case } & \multirow[t]{2}{*}{$\begin{array}{c}\text { Max V } \\
\text { deviation at } \\
\text { bus } 6\end{array}$} & \multicolumn{2}{|c|}{ VUF at bus 6} & \multicolumn{2}{|c|}{$\begin{array}{c}\text { Neutral potential } \\
\text { at bus } 6\end{array}$} \\
\hline & & & $\begin{array}{c}\text { Mean } \\
\text { Val. }\end{array}$ & $\begin{array}{l}\text { Max } \\
\text { Val. }\end{array}$ & $\begin{array}{l}\text { Mean } \\
\text { Val. }\end{array}$ & $\begin{array}{l}\text { Max } \\
\text { Val. } \\
\end{array}$ \\
\hline \multirow{3}{*}{$\# 1$} & Base & $-10.1 /+10.0 \%$ & $0.71 \%$ & $1.72 \%$ & $1.96 \%$ & $5.05 \%$ \\
\hline & OLTC & $-6.5 /+5.0 \%$ & $1.04 \%$ & $2.49 \%$ & $2.03 \%$ & $5.31 \%$ \\
\hline & OLTC+Qreg & $-4.0 /+4.5 \%$ & $1.08 \%$ & $2.59 \%$ & $1.88 \%$ & $4.54 \%$ \\
\hline \multirow{3}{*}{$\# 2$} & Base & $-15.0 /+15.0 \%$ & $1.03 \%$ & $2.32 \%$ & $3.11 \%$ & $7.84 \%$ \\
\hline & OLTC & $-11.0 /+11.2 \%$ & $1.45 \%$ & $3.24 \%$ & $3.29 \%$ & $8.32 \%$ \\
\hline & OLTC+Qreg & $-7.0 /+8.4 \%$ & $1.75 \%$ & $4.14 \%$ & $2.75 \%$ & $6.56 \%$ \\
\hline \multirow{3}{*}{ \#3 } & Base & $-4.0 /+13.0 \%$ & $0.56 \%$ & $1.63 \%$ & $1.48 \%$ & $4.08 \%$ \\
\hline & OLTC & $-2.0 /+8.8 \%$ & $0.79 \%$ & $2.01 \%$ & $1.61 \%$ & $4.42 \%$ \\
\hline & OLTC+Qreg & $-2.0 /+4.5 \%$ & $1.17 \%$ & $4.05 \%$ & $1.41 \%$ & $3.95 \%$ \\
\hline \multirow{3}{*}{ \#4 } & Base & $-6.0 /+16.2 \%$ & $0.72 \%$ & $1.89 \%$ & $2.08 \%$ & $5.47 \%$ \\
\hline & OLTC & $-3.0 /+12.0 \%$ & $0.95 \%$ & $2.03 \%$ & $2.23 \%$ & $5.89 \%$ \\
\hline & OLTC+Qreg.mod & $-2.0 /+7.0 \%$ & $1.41 \%$ & $4.47 \%$ & $1.89 \%$ & $4.86 \%$ \\
\hline
\end{tabular}




\section{CONCLUSIONS AND FUTURE WORKS}

This work presented the simulation studies to develop and test the feasibility of a decoupled three-phase OLTC MV/LV transformer with the objective of improving the distribution network power quality. Analysis have been performed considering the simultaneous actions of an additional control system, based on the management of the reactive power provided by the PV plants on the basis of local real time voltage and active power measurements, according to a specific $Q=f(V, P)$ regulation law.

At first, very unbalanced PV connection scenarios have been considered: the joint actions of the two controllers enabled an increase of the PV hosting capacity of the grid, since acceptable phase-neutral and neutral-ground voltages have been guaranteed. Afterwards, for the next scenarios, a more realistic distribution of the installed PV power among the three phases has been contemplated: results showed a further enhancement of the maximum acceptable PV hosting capacity.

The results showed that, with significantly large amount of PV installed, many undesired fluctuations may appear, making the control system unstable. The cause is due to the gain of the Q-regulation law, therefore a different $Q=f(V, P)$ law with the same dead band and a lower gain has been considered in order to make the system stable again. A conclusion to this is that the DSO is supposed to take into account that, whether Q-regulation laws with a too high gain are issued, fluctuations could take place if a considerable PV power is installed in the LV grid. In this case it should provide regulation laws with a smaller gain, making it possible to accept such a high PV penetration.

In all the scenarios, the Voltage Unbalance Factor has grown compared to the operative cases without the reactive power control by PVs, as a result of the opposite trends in the positive and negative sequences magnitudes. So, even though the additional Q-control system brings benefits in terms of phase-neutral voltage deviations and neutral potential, it also involves undesired increases of the VUF, since its control logic does not consider any voltage sequences analysis. These criticalities need to be considered and taken into account by the DSO, which has to guarantee that this index lies below the limits issued by the national and European technical standards, looking for other regulating actions.

The objective of future works is to investigate further enhancements of the coordinated actions of the controllers and to perform practical tests: the decoupled three-phase onload tap-changer transformer will be experimentally tested using the SYSLAB-PowerLab.DK experimental facility at the DTU Risø Campus in 2015.

\section{ACKNOWLEDGEMENTS}

The authors acknowledge the financial support to this work given by the Danish EUPD program for the project 'Energy Saving by Voltage Management', under the grant number
5996648995411. The authors thank the team of PSS Energy $\mathrm{A} / \mathrm{S}$ and Dong Energy for the interesting discussions.

\section{REFERENCES}

M. Braun, T. Stetz, R. Bründlinger, C. Mayr, K. Ogimoto, H. Hatta, H. Kobayashi, B. Kroposki, B. Mather, and M. Coddington, "Is the distribution grid ready to accept large-scale photovoltaic deployment? State of the art, progress, and future prospects," Prog. photovoltaics Res. Appl., vol. 20, no. 6, pp. 681-697, 2012. R. Caldon, M. Coppo, and R. Turri, "Distributed voltage control strategy for LV networks with inverter-interfaced generators," Electr. Power Syst. Res., vol. 107, no. 0, pp. 85-92, Feb. 2014.

[3] K. Knezović, M. Marinelli, R. J. Møller, P. B. Andersen, C. Træholt, and F. Sossan, "Analysis of Voltage Support by Electric Vehicles and Photovoltaic in a Real Danish Low Voltage Network," Universities Power Engineering Conference (UPEC), 2014 Proceedings of the 49th International, pp.1-6, Cluj Napoca, 2-5 Sep. 2014

[4] A. Kechroud, P. F. Ribeiro, and W. L. Kling, "Distributed generation support for voltage regulation: An adaptive approach," Electr. Power Syst. Res., vol. 107, no. 0, pp. 213-220, Feb. 2014.

[5] A. Einfalt, F. Kupzog, H. Brunner, and A. Lugmaier, "Control strategies for smart Low voltage grids - the project DG DemoNet smart LV grid," in Integration of Renewables into the Distribution Grid, CIRED 2012 Workshop, 2012, no. 0238, pp. 1-4.

[6] I. Leisse, O. Samuelsson, and J. Svensson, "Coordinated voltage control in medium and low voltage distribution networks with wind power and photovoltaics," in 2013 IEEE Grenoble Conference, 2013, pp. 1-6.

[7] M. Stifter, B. Bletterie, H. Brunner, D. Burnier, H. Sawsan, F. Andren, R. Schwalbe, A. Abart, R. Nenning, and F. Herb, "DG DemoNet validation: Voltage control from simulation to field test," in Innovative Smart Grid Technologies (ISGT Europe), 2011 2nd IEEE PES International Conference and Exhibition on, 2011, pp. $1-8$

[8] M. Stifter, R. Schwalbe, W. Tremmel, S. Henein, H. Brunner, B. Bletterie, A. Abart, F. Herb, and R. Pointner, "DG DemoNet: Experiences from volt/var control field trials and control algorithm advancements," in 2012 3rd IEEE PES Innovative Smart Grid Technologies Europe (ISGT Europe), 2012, pp. 1-7.

[9] M. Stifter, B. Bletterîe, and F. Herb, "DG DemoNet: Impact of VOLT/VAR control on increasing the voltage band reserve Results from field trial validations," in Electricity Distribution (CIRED 2013), 22nd International Conference and Exhibition on, 2013, no. 0508, pp. 1-4.

[10] M. Coppo, R. Turri, M. Marinelli, and X. Han, "Voltage Management in Unbalanced Low Voltage Networks Using a Decoupled Phase-Tap-Changer Transformer," Universities Power Engineering Conference (UPEC), 2014 Proceedings of the 49th International, pp1-6, Cluj Napoca, 2-5 Sep. 2014.

[11] "DONG Energy." [Online]. Available: http://www.dongenergy.com/.

[12] "IEEE Task Force on Load Representation for Dynamic Performance, Load representation for dynamic performance analysis," IEEE Trans. Power Syst., vol. 8, no. 2, pp. 472-482, 1993.

[13] "Italian Technical Standard CEI 0-21.” Norma Italiana, 2012.

[14] "German Technical Standard VDE-AR-N 4105." FNN - Forum Netztechnik / Netzbetrieb im VDE, 2011.

[15] "European Technical Standard EN 50160," 2011.

[16] P. Pillay and M. Manyage, "Definitions of voltage unbalance," IEEE Power Eng. Rev., vol. 22, no. 11, pp. 49-50, 2002. 